\title{
Strategic Research on Effective English Communication
}

\author{
Guoqiang Liao \\ Sichuan University of Science \& Engineering, Zigong 643000, China \\ Email: gqliao408@yahoo.com.cn
}

\begin{abstract}
As the most popular language in the world, English has become a very important tool in communication among persons from different countries .So, communicative competence is very important and necessary for university students. However, the teaching and learning of oral English is not optimistic in our country. This article focuses on the strategies of improving students' ability in English communication.
\end{abstract}

Index Terms - strategies, communicative, competence, improvement

\section{FACTORS AfFecting StUdents’ COMMUniCATIVE COMPETENCE}

In recent years, nearly every college or university has been increasing some kinds of exams so as to improve the students' ability in oral English. However, the examinations seem not to work as well as they hoped, though some of which have some positive effects. Although many students have been learning English for years, quite a few of them still find it difficult to express themselves clearly in English. Why is it like this?

1. Many teachers have been faced with the dilemma of having more than 60 students in a Chinese university 'English Conversation' class for non-English majors, which decreases the time for any student-teacher interaction. They have few chances to practice oral English. Moreover, students have little or no acceptance of or responsibility for their own learning. In most Chinese universities, students are grouped together by major (for example, all Law students together). They are expected to take their major classes together with the same group of people throughout their entire undergraduate academic career at the university. Almost all university classes meet twice a week, with an expected final exam at the end of the semester. This is obviously a challenging situation for developing communicative competence in English for non-English majors. The number of more than 60 students is also a challenge for the teacher with the goal of reaching that purpose.

2. Chinese students are given six years of English Language instruction in most junior-high and senior-high schools. These six years are mostly translation-based; the students rarely, if ever, need to speak English at all. High-school students receive considerable passive exposure to grammar, translation, vocabulary and semantic information from written sources, but little exposure to communicative situations, or required to actively use English.

3. Nearly all students are taught the same material and there is a limited number of approved texts. Though some materials taught in secondary school English classes are communicatively based, they are mainly directed toward students' preparation for the all-important university entrance examinations, which principally test a student's general ability to memorize. English exams are a compulsory part of all these exams. Usually, the English section of an entrance exam consists of long reading passages, followed by translation exercises, a small number of "reading comprehension" questions (actually testing the student's ability to pick out details from the text), and a few vocabulary or grammar questions. Becoming more common is a listening passage with a few questions. There are no communicatively based university examinations.

4. English as a Foreign Language is often taught in China as a passive subject, not an active one. There is little exposure to interaction in the English-language classroom. Now most ESL classrooms at universities are teacher-oriented and teacher-directed. Furthermore, classes are large (frequently more than 50-80 students in a class), which decreases the time for any student-teacher interaction.

The result of the combination of these factors is that:

1) Students generally have low confidence in their own communicative ability;

2) Students generally have low motivation to learn to communicate in English, and a high motivation to memorize English in a non-communicative form;

3) Students have little or no understanding of ability to reproduce English sounds; and

4) Students lack the ability to creatively express their own thoughts and opinions.

\section{TRAining StUdents’'AbiLity OF LANGUAGE-LEARNING}

\section{A. The Ability of Language Speaking is the Most Important Part in Language Learning}

In the modern life, language-speaking is greatly changed by people .It reflects that people are paying more and more attention to language-speaking, because it's considered as an important tool in education. And we can see that the training of language-speaking is very important in deed. To improve students 'ability of listening, speaking or practicing 
is an important part in foreign language learning. For the purpose of testing whether students are scientific and all-round in language learning, the test must contain oral test, listening test and writing test. We should know that communication is an overall ability of training, containing listening, reading, speaking, writing, and so on.

\section{B. The English Communication is Needed by Society}

China is trading and exchanging with many countries, which is frequently linked with foreign affairs or business. As the most popular language that is spoken pretty widely in international communications, English is extending to a lot of people, most of whom recognize it's very important to make themselves masters of English in modern society. What's more, how can you communicate with foreigners if you are not able to speak foreign language, especially English? For example, if you will become a volunteer of Olympic Games, or you want to get a high occupation and high salary in foreign companies, or you want to do business with them, effective English communication will be the first step.

\section{Improving the Ability in Spoken English Communication}

1) The ability in English communication must contain two parts. One is knowledge; the other is the ability of using it. Although these kinds of knowledge may not be widely used, it can reflect the knowledge existing in your mind. If we have enough knowledge of language, one day we will show them out in a suitable situation. If we don't have much more "input" and the accumulation of linguistic knowledge, we can't make the real "communication" and can't get the goal of improving the ability of spoken language in communication.

2) Students should recognize the role in language learning. Students being the core have been accepted by most teachers in the spoken instruction. The theory emphasizes that teachers attach more importance of the psychology to English communication. Specifically, they need to encourage students to use the language. The students should express their thoughts actively as often as they can both in and outside of class, reinforcing the "input" of the language. However, "the center of students" doesn't mean that teachers have no effect in the spoken-language education. In fact, the teacher is a guider, instructor, manager, and so on. He plays the key role in the spoken language instruction, supplying and creating the situation of the language communication.

3) Non-verbal communication is also an important part in communication. If two people are talking about something, it is said that only about 35 percent of 'information is transformed from linguistics. Then the rest 65 percent information is transformed from non-verbal communication. For so long a time, we have only been related to verbal communication when we are talking about the spoken language communication. But in fact, as one of the communication's key elements, it only reinforces the use of the language; and the non-verbal communication can get the aim of using the language. Therefore, we could improve the ability of the students' spoken language in communication.

\section{Strategies of Developing Students’ Communicative Competence}

\section{A. Communicative Learning and Cooperative Learning.}

Outside the classroom, the instructor may have limited ability to affect their students. Rather, the instructor can select and develop strategies to maximize learning opportunities in class. Effective EFL teaching is based upon two complementary concepts: communicative learning and cooperative learning. Communicative learning can be conceived of as a sub-set of cooperative learning. Cooperative learning is a teaching approach applied in a vast array of subjects. Communicative learning is particularly appropriate to language learning. A further concept, developing students' "communicative competence", is introduced as the principal goal of communicative learning.

"Cooperative learning" is a situation where students learn together, based on group work; contrasting this educational method is "competitive learning," where students compete against each other in a learning situation. However, cooperative learning experiences promote higher academic achievement than do competitive learning experiences. Cooperative learning suits communicative English-language classes well. Communicating in English is based on cooperation between students to negotiate meaning and understanding with each other. This is contrasted with the traditional reading and translation-based classes, which by comparing the students to arrive at grades are competitive and penalize cooperative learning. Combination of cooperative and competitive goal structures is feasible, by having cooperative learning groups compete against each other.

By contrast, a communicative language learning approach emphasizes:

The student having a central role; the primary goal is the ability to communicate; meaning is paramount, and language learning is contextualized; and an active learning approach and active learning strategy.

\section{B. Classroom Activities.}

Developing communicative competence is associated with the following classroom activities:

The students speaking and listening for most of the lesson;

The students participating intensively in the class;

A focus on comprehensible and meaningful input and output;

Involving the students in different kinds of roles, necessitating the use of different styles of speaking;

Students practice using conversational routines and expressions, to use authentic English communicatively;

Information sharing; 
Requiring students to develop meaning collaboratively by peer interaction;

The students manipulating language in a substantial and meaningful way;

The teacher providing information about language usage;

The teacher providing timely and meaningful feedback;

A positive and supportive environment that encourages language manipulation and exploration; and

A learner-centered environment, with the teacher acting as facilitator.

A short comment on peer interaction: the acquisition of English-language speaking experience is not the transfer of relevant input from a more capable person to a less capable person, but rather the development of communication strategies through interaction. Small group work is preferred, as it encourages:

Requiring students to actively participate in all class activities;

Group initiatives;

Formation of communicative interaction determined by each group;

Delegation of the responsibility for learning to the groups, so students take responsibility for their own learning;

Working towards established goals within each group.

Functioning well without a leader;

Students having a positive attitude towards each other and towards the class work; and

Cooperative behavior.

\section{The Instructor's Role.}

The instructor's role is based upon defining class goals, and facilitating cooperative learning and communicative learning.

There is a strong need in the classroom for clarity of goals: the goals themselves, the means of achieving the goals, and the means of assessment. Non-English majors in a required English Conversation class seem to function best when goals are clearly articulated and attainable; this is in contrast to English majors, who are more interested in and capable of determining their own English study goals. The instructor in a required English conversation class for non-English majors is better equipped to determine class goals, their means of achievement, and their assessment. The student still retains the flexibility to manipulate the language freely, as they see fit.

Cooperative learning is centered on students working together in class, and is based upon small-group work.

Teachers can facilitate cooperative learning by:

1) Playing a facilitating role: supporting and encouraging students' self-directed study efforts, by being available to answer student questions during practice time.

2) Encouraging positive interdependence: group members can only succeed if they work together. This can be fostered in numerous ways by the teacher, particularly:

assessing a group as one entity instead of individually;

assessing group performance based upon their communication, which requires dynamic input from all members of a group;

facilitate some degree of competitiveness between the groups, to positive interdependence with the cooperative small group.

3) Ensuring group goal similarity: the more similar the goals of the group, the more cooperative their activities will be. The teacher defining class goals will provide focus to the activities of the group.

\section{CONCLUSION}

Teachers and students alike generally enjoy and learn from these techniques. They solve the problem of how to work with a very large class, yet allow the teacher to interact with individual students. Students work in English to their own level of interest and ability in a learner-centered classroom. Communication strategies are practiced and reinforced. The language used in class is meaningful and communicative. There is no such thing as "the perfect teacher." Giving a homily on what "good teachers" do appears to be unhelpful and unrewarding to those who want to improve their own practices. A far more helpful approach seems to be the study of teachers' beliefs, which inform and shape their actions. Constructivism lies at the heart of this endeavour, as it offers valuable insights into the cognitive as well as affective aspects of the relationship between teachers and their self-images, and teachers and students. Teaching is not merely information or knowledge, but mainly an expression of values and attitudes. What teachers usually get back from their students is what they themselves have brought to the teaching-learning process.

\section{REFERENCES}

[1] Gow, L. and D. Kember. (1993). Conceptions of teaching and their relationship to student learning. British Journal of Educational Psychology, 63, 20-33.

[2] Von Glasersfeld, E. (1995). Radical Constructivism. London: Falmer.

[3] Williams, M. and R. L. Burden. (1997). Psychology for Language Teachers: a social constructivist approach. Cambridge: Cambridge University Press.

[4] West, B. (1997). Talk Your Head Off. Upper Saddle River, NJ: Prentice-Hall Regents. 
[5] Samovar, L. A., \& Porter, R. E. (2004). Communication Between Cultures (5th ed.). Beijing: Peking University Press.

[6] Gudykunst, W. B. (Ed.). (2005). Theorizing About Intercultural Communication Guide. Mason, Ohio: Thomson South-Western.

Guoqiang Liao was born in Zigong, China in 1965. He received his M.A. degree in linguistics from Southwest University, China in 1997.

He is currently a teacher in the School of Foreign Languages, Sichuan University of Science \& Engineering, China. His research interests include English language and culture.

Mr. Liao is a member of Sichuan Translators Association. 